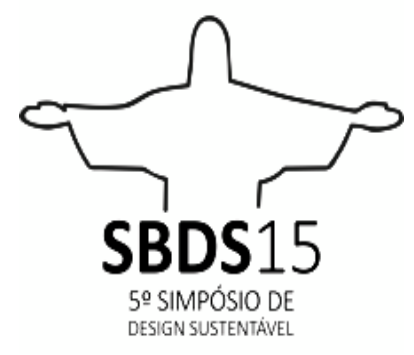

Rio de Janeiro - RJ

De 11 de novembro a 13 de novembro de 2015

\title{
ECOBAG: 0 desafio do design na geração de solução que promova o consumo sustentável
}

\author{
CANCIAN, Fernanda; Especialista em Gestão do Design; UEL; can.fernanda@live.com \\ PEREIRA, Marco; Professor Doutor; FEB - UNESP/Bauru; pereira@feb.unesp.br \\ BARATA, Tomas Queiroz Ferreira; Doutor; UNESP - FAAC, campus Bauru/SP. \\ barata@faac.unesp.br
}

\begin{abstract}
Resumo: Frente um cenário de consumo excessivo, geração de resíduos a níveis alarmantes, fez-se necessário compreender os fatores limitantes para a retirada das sacolas descartáveis, provenientes de material derivado de petróleo, do mercado. Diversas iniciativas públicas, no Brasil, já foram implementadas sem muito sucesso. Além da proibição das sacolas não ser aceita pelos consumidores, as opções de ecobags (sacolas ecológicas) disponíveis no mercado apresentam diversos problemas ambientais quando analisado seu ciclo de vida. Baseado nesse cenário, o presente estudo tem como objetivo discorrer sobre os desafios do design no desenvolvimento de ecobags de maneira amplamente sustentável. A metodologia empregada iniciou com pesquisa exploratória, através de levantamento bibliográfico e documental, sendo a base para a pesquisa explicativa, quando foram evidenciados os principais desafios a serem superados pelo design. Acredita-se que as soluções devam ser específicas, de acordo com a realidade de cada município, assim como na cidade de São Paulo que conseguiu implementar a lei de banimento das sacolas, através do design de ecobags padronizadas.
\end{abstract}

Palavras-chave: Sustentabilidade; ciclo de vida; design; sacolas plásticas; ecobag.

Abstract: Front an excessive consumption scenario, waste generation at an alarming rate, it was necessary to understand the limiting factors to withdrawal from the market the disposable bags made with material derived of oil. Several public initiatives in Brazil have already been implemented without successful. In addition to the banishment of the bag not be accepted by consumers, the ecobags (ecological bags) available on the market presents many environmental problems when analyzed its life cycle. Based on this scenario, the present study aims to 
discuss the challenges of design in the development of ecobags widely sustainably. The methodology began with exploratory research, through literature and documentary, being the basis for the explanatory research, when the major challenges to be overcome by the design were highlighted. It is believed that the solutions have to be specific, according to the reality of each municipality, as well as in São Paulo that managed to implement a law banning the bags through standardized ecobags design.

Key Word: sustainability; life cycle; design; Plastic bags; ecobag.

\section{INTRODUÇÃO}

O consumo ultrapassa os limites, sendo que apenas $20 \%$ da população mundial consomem $80 \%$ dos recursos de nosso planeta conforme exposto por Vezolli \& Manzini (2008). As sacolas provenientes de material derivado do petróleo, distribuídas por estabelecimentos comerciais gratuitamente, fazem parte deste consumo exagerado. Elas vieram para o Brasil na década de 1980, fazendo parte da filosofia "tudo descartável" e permaneceram até os dias de hoje (PEREIRA, 2007). O Ministério do Meio Ambiente (2009) estima que o país produza 135 bilhões de sacolas por ano. Dessa forma, as sacolas são um grande problema ambiental e chegam a atravessar oceanos e florestas, gerando grandes prejuízos à natureza, pois sua degradação demanda centenas de anos.

Em combate a essa situação, muitas cidades no mundo passaram a banir a distribuição das tradicionais sacolas de PEAD (Polietileno de alta densidade). Porém, em diversos municípios do Brasil os consumidores não se adequaram as opções de sacolas, descartáveis e reutilizáveis, disponíveis no mercado, fazendo com que a lei deixasse de ser aplicada em diversas cidades. Além disso, as sacolas denominadas ecobags (sacolas ecológicas) disponíveis no mercado foram criadas sem um estudo de design, podendo ser ainda mais prejudiciais ao ambiente, quando não utilizada de forma consciente, conforme relatório desenvolvido na Inglaterra pela Environment Agency (2006), testes mostraram que de acordo com o número de utilização, as sacolas de PEAD, podem ser menos impactantes ao meio ambiente, que outras opções disponíveis no mercado, pois leva pouco material na sua fabricação. No entanto, esse estudo foi feito com dados locais, o que não reflete necessariamente a realidade brasileira.

Desta forma, esse estudo tem como propósito evidenciar as razões pelas quais a retirada das sacolas de PEAD do mercado se faz necessário, os pontos críticos nos quais torna essa mudança tão complexa, sendo muitas vezes inviabilizada, e a importância do design ser trabalhado de forma ampla por meio de ferramentas que as tornem sustentáveis, desenvolvendo uma opção que substitua de forma eficaz as sacolas descartáveis e seja aceita pelo consumidor, reduzindo efetivamente os danos causados a natureza.

\section{MATERIAIS E MÉTODOS}

O presente estudo iniciou com pesquisa documental e bibliográfica de forma geral e exploratória (SEVERINO, 2007) abordando os seguintes temas: os problemas 
causados pelas sacolas descartáveis, os locais no mundo onde as sacolas foram banidas e a importância do design no desenvolvimento de uma solução.

A pesquisa explicativa, mais específica, teve como objetivo indicar os pontos determinantes que tornam o desenvolvimento de uma ecobag um desafio ao design (PRODANOV, 2013). Nessa fase, foi realizado levantamento dos pontos críticos, relacionados a aspectos ambientais e de qualidade das sacolas de petróleo e de diversas opções disponíveis no mercado. Passando para o levantamento documental expondo a complexidade dessa mudança em diversas cidades do Brasil e o caso do município de São Paulo, a cidade mais populosa do país, que conseguiu através do design implementar a lei que bane as sacolas de material derivado do petróleo depois de muitas tentativas sem sucesso. Finalizando a pesquisa explicativa, foram abordados os principais pontos a serem trabalhados através do design para a obtenção de uma solução que atenda as necessidades da população de forma sustentável. Nesse caso, o próprio desenvolvimento do design apresenta complexidade, na análise do ciclo de vida (Lyfe Cycle Design) das sacolas e na difícil tarefa do levantamento desses dados.

Assim, foram abordadas as três variáveis colocadas por Manzini \& Vezzoli (2011) como fundamentais no controle do impacto ambiental, sendo a ecoeficiência das tecnologias aplicadas na definição do material menos agressivo, a normal tendência da população no aumento pela procura do bem estar que deverá ser sanada pela nova solução a ser desenvolvida, e a ecoeficiência dos sistemas técnicos, podendo ser consideradas apenas soluções que reduzam o consumo de recursos a $10 \%$ se comparado ao utilizado atualmente. Essa abordagem aponta a complexidade e os aspectos a serem considerados em novos desenvolvimentos.

\section{RESULTADOS E DISCUSSÕES}

\subsection{Pesquisa Exploratória: $O$ contexto atual}

Os impactos ambientais causado pelo consumo indiscriminado podem gerar o esgotamento dos recursos, o aquecimento global, a redução na camada de ozônio, a poluição, acidificação, eutrofia, toxinas no ar e no solo, lixos e descartes. As dimensões desses impactos podem ser locais, regionais, ou até mesmo a nível global, como por exemplo, causando mudanças climáticas (MANZINI; VEZZOLI, 2011). A distribuição gratuita das sacolas, aliado a sua má qualidade, contribuem para consumo descontrolado. A Autoridade Municipal de Limpeza Urbana - AMLURB (2015) apresenta uma estimativa de consumo de 59 unidades de sacolas por pessoa mensalmente. Dessa forma, é comum encontrar sacolas vagando pelas ruas, parques, nos mais diversos lugares do planeta, como em áreas remotas da Antártida (GREENPEACE, 2010).

Buscando a redução desse consumo, diversos países baniram a distribuição de sacolas descartáveis, como é o caso da Irlanda, em 2002, um dos primeiros países a tomar uma medida sobre a produção descontrolada de sacolas plásticas, implantando a PlasTax, um imposto cobrado ao consumidor por cada unidade distribuída. 0 resultado foi uma angariação de fundos destinados a projetos ambientais e uma redução de $90 \%$ no consumo de sacolas. Em algumas regiões da Índia a lei implementada em 2010, foi uma iniciativa adotada para reduzir o impacto ambiental, (a morte de vacas por ingestão de plástico foi um motivador), que se fortaleceu 
através de multas ou até cinco anos de prisão. Na Austrália, alguns comerciantes se uniram para estimular o uso das Ecobags, fornecendo diversos modelos, dentre eles bolsas térmicas para produtos quentes ou refrigerados (BARBOSA, 2012).

Assim, o desenvolvimento de opções a substituir as sacolas de PEAD devem se mostrar ecológicas e também atender as necessidades do consumidor, se fazendo um motivador a mudança. Essas sacolas, assim como uma embalagem, têm a função de transportar, proteger, acondicionar, garantindo a qualidade do produto. Ela também deve ser prática e funcional atendendo o novo perfil da sociedade, que condiciona o indivíduo a ter cada vez menos tempo, além de ser sustentável (THE CONSUMER GOODS FORUM, 2011). Por expressar o primeiro contato com o cliente, às sacolas, também tem a função de comunicar, levando informações importantes ao conhecimento do consumidor, por exemplo, o correto descarte e o peso suportado. A ergonomia da embalagem também deve ser avaliada, evitando que uma pessoa transporte mais peso que o recomendado. Dessa forma, o design tem a função de transformar os elementos artificiais do cotidiano em objetos voltados a satisfazer as necessidades da sociedade, garantindo harmonia entre ambos através de relações físicas, psíquicas e emocionais (BONI; SILVA; SILVA, 2014).

Para melhor expor os desafios do design na busca de solução ecológica, o presente estudo apontou de forma explicativa os pontos críticos a serem considerados em novos desenvolvimentos, entregando ao consumidor uma opção de sacola que seja aceita e venha a contribuir com o meio ambiente.

\subsection{Pontos críticos apresentados pelas sacolas disponíveis no mercado}

As populares sacolas descartáveis, feitas à base de petróleo (Polietileno de Alta Densidade), não têm grande resistência mecânica e rasgam facilmente durante o transporte de produtos. Conforme aponta relatório de teste do INMETRO realizado após inúmeras reclamações, feitas por consumidores (BORGES, 2007).

O teste analisou 18 marcas de sacolas, conforme norma NBR 14.937 - Sacolas plásticas tipo camiseta - requisitos e métodos de ensaio, publicada em 2005 pela ABNT. Todas as marcas apresentaram algum tipo de não conformidades, confirmando a falta de segurança. Dessa forma, o consumidor passou a utilizar mais sacolas que o necessário, para o transporte de poucos produtos. Quando em boas condições, as sacolas normalmente eram reutilizadas para colocação de lixo, porém, nem todas têm esse destino.

Outro problema é o tempo de decomposição previsto para esse material, que pode chegar a 500 anos (SANTOS, et al., 2012). Da mesma forma, as opções criadas para a sua substituição também apresentam problemas ambientais, quando analisado o seu ciclo de vida, desde a extração até o seu descarte. Por exemplo, para um município que dispõe apenas de aterros sanitários, as sacolas descartáveis oxidegradáveis não são recomendadas, pois não tem sua degradação facilitada nessas condições. Com relação às sacolas descartáveis fabricadas com adição do amido de milho, parte do material permanece na natureza de forma fragmentada, gerando a poluição invisível, conforme apontado por Santos, A. S. F. et al. (2012).

Um estudo realizado pelo Environment Agency (2006) na Inglaterra sobre os impactos causados pelas sacolas em seu ciclo de vida comparou os sete tipos de materiais mais comumente utilizados, mostrando que a quantidade de vezes que a 
sacola é utilizada impacta diretamente nos resultados, dessa forma, foi feita a avaliação de nove aspectos ecológicos, considerando o mesmo peso e volume transportado por cada sacola. Os resultados mostraram que dependendo da quantidade de reutilização das sacolas, as de PEAD são as mais ecológicas, pois o volume de material utilizado na sua fabricação é o menor se comparado com qualquer uma das outras opções, até mesmo com relação às sacolas oxi-degradáveis. As sacolas de TNT (Tecido não tecido) precisariam ser utilizadas pelo menos quatorze vezes para se mostrar eficientes, as sacolas de papel precisariam ser utilizadas quatro vezes, para compensar a sua produção. As sacolas de algodão precisariam ser reutilizadas 173 vezes para compensar todo o processo desde os agrotóxicos utilizados no plantio do algodão, até seu descarte. Porém, é importante lembrar que esses resultados não se aplicam no Brasil, pois as variáveis de extração, produção, utilização e descarte são diferentes em cada município. Além disso, por serem mais leves, as sacolas de PEAD, se tornam menos resistentes, fazendo com que seja necessária a utilização de mais sacolas no transporte de poucos produtos, gerando o consumo abusivo.

Desse modo, o presente cenário aponta a complexidade na definição do material a ser utilizado, mostrando que até o momento as soluções encontradas, na maior parte dos casos, foram parciais, sendo necessário o desenvolvimento de solução que analise o ciclo de vida de acordo com a realidade de cada localidade.

\subsection{A complexa mudança e como São Paulo obteve resultados através do design}

No Brasil, algumas cidades têm aderido ao banimento das sacolas de PEAD, como por exemplo Belo Horizonte, onde a lei municipal $N^{\circ} 9.529$ de 27 de fevereiro de 2008, passou a ser aplicada em abril de 2011, decretando o fim das tradicionais sacolas plásticas. Isso obrigou os consumidores a mudarem seus hábitos, adotando embalagens retornáveis, ou caixas de transporte, disponibilizados pelos comerciantes (APAS, 2012). Porém, essas caixas de transporte acabam indo para o lixo comum, o que não se mostra uma boa prática principalmente em cidades onde não existe coleta seletiva. O ideal é que o supermercado envie essas caixas diretas para a reciclagem evitando novas contaminações.

No Rio de Janeiro, a lei estadual N 5.502 de 2009, que entrou em vigor em 2010, prevê a substituição de sacolas plásticas por retornáveis, tendo a opção de conceder desconto de $\mathrm{R} \$ 0,3$ a cada cinco itens levados pelo consumidor sem sacola plástica, ou, até mesmo, um quilo de feijão ou de arroz para cada 50 sacolas devolvidas ao estabelecimento comercial. Na capital carioca, os comerciantes optaram pelo desconto, mas isso não atraiu o interesse do consumidor, pois apenas $2 \%$ aderiram ao novo perfil de compra (COSTA, 2015).

Em 2012, diversas cidades do Estado de São Paulo como Franca, Barretos, Bebedouro, São José do Rio Preto, Guarujá, Sorocaba e Presidente Prudente, após alguns meses da aplicação da lei que proíbe a distribuição gratuita das sacolas, voltaram atrás, após inúmeras reclamações de consumidores (BONATO, 2012). No município de Birigui, também interior do estado de São Paulo, a lei no 5322/2010 que obriga estabelecimentos comerciais a distribuir apenas sacolas biodegradáveis, ou oxidegradáveis, também não está sendo cumprida, e tão pouco resolve o problema, pois o município dispõe apenas de aterro sanitário para descarte do lixo e conforme comentado essas não tem sua decomposição facilitada em aterros. 
Um bom exemplo no qual a implementação da lei foi facilitada pelo design, ocorreu no município de São Paulo. Em 2011, foi sancionada a lei $n^{\circ} 15.374$, que previa o fim da distribuição gratuita de sacolas plásticas, porém, a lei não foi regulamentada. Em fevereiro de 2012, a Associação Paulista de Supermercados (APAS) e o MP (Ministério Público) firmaram um Termo de Ajustamento de Conduta (TAC), fazendo com que os estabelecimentos comerciais deixassem de distribuir gratuitamente as sacolas, passando a vender diversas opções de sacolas por diferentes preços, chamadas de Ecobag. Dessa forma, os clientes teriam que levar sacolas reutilizáveis ou pagar pela Ecobag. Antes que o Ministério Público (CMSP) homologasse o TAC, em junho do mesmo ano, a Associação SOS Consumidores, ajuizou uma Ação Civil Pública contra a APAS e as sacolas descartáveis voltaram a ser distribuídas (SANTIAGO, 2015).

Somente em outubro de 2014, o Tribunal de Justiça de São Paulo declarou a lei constitucional e ela foi regulamentada, sendo que a sua fiscalização e obrigatoriedade iniciaram em abril de 2015, após a publicação do Decreto regulamentador no 55.827 de 06 de janeiro de 2015, que especifica os novos modelos de sacolas descartáveis a serem adotados.

Conforme determinado no decreto, a Associação Comercial de São Paulo (2015) explica que as novas sacolas devem ter ao menos $51 \%$ de sua composição derivada de material renovável, que, além de seguir um padrão internacional, é menos nocivo à natureza. Nessa nova configuração, as sacolas têm maior resistência mecânica, devendo suportar o peso máximo de $9,9 \mathrm{~kg}$ possibilitando o transporte de produtos mais pesados. Ergonomicamente essa resistência atende a maior parte da população, conforme defende o ortopedista pediátrico e professor na Santa Casa de São Paulo, Claudio Santili (AQUINO, 2014), que recomenda transportar peso máximo de $10 \%$ do peso corporal. As sacolas ficaram aproximadamente $40 \%$ maiores que as tradicionais, tendo dimensões definidas de 48 centímetros por 55 centímetros. Esses pontos podem contribuir com a redução no consumo de sacolas, quando reutilizadas para compras futuras ou para a separação correta do lixo.
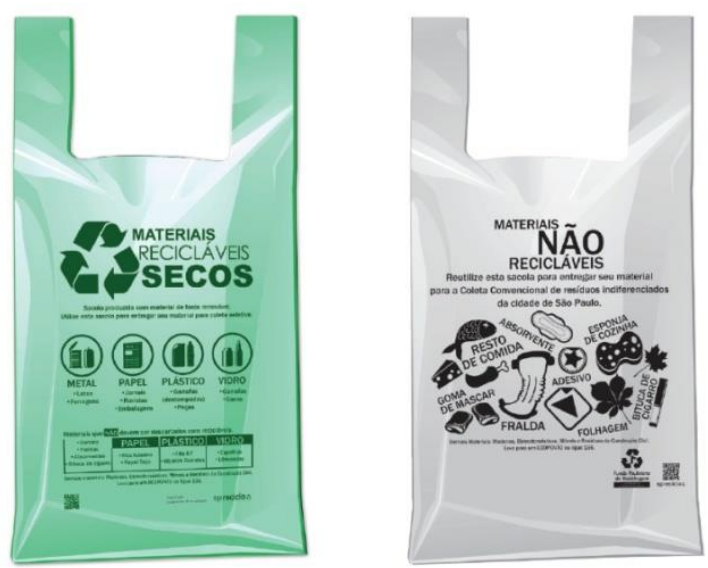

Figura1 - Sacolas definidas pelo decreto $n=55.827 / 2015$. Fonte: Associação Comercial São Paulo 2015. 
As sacolas também receberam um caráter educativo, comunicando ao consumidor informações de descarte. As sacolas verdes deverão ser utilizadas para o lixo reciclável, e as sacolas cinza para o lixo orgânico, facilitando, de forma didática, o entendimento de suas respectivas funções. Segundo o Redeg (2004), esses detalhes são fundamentais para a transmissão da mensagem, pois, pensando-se no receptor, a mensagem tende a ser trabalhada de forma clara e objetiva. Mesmo com a arte prédefinida, os hiper/supermercados podem aplicar seus respectivos logotipos nas sacolas, garantindo, ainda, a divulgação da marca do estabelecimento, como era feito anteriormente.

O consumidor teve pequenas mudanças na sua rotina de consumo e descarte, que, além de pensar em qual sacola deverá descartar cada material, ele deve se atentar, no momento da compra, à quantidade de sacolas de cada cor. Se colocar toda a compra em sacolas cinza, não terá sacolas para o lixo descartável. A padronização, comum a todos os estabelecimentos facilita a formação da consciência de consumo e descarte. Essa medida acaba por incentivar a população a fazer a correta separação do lixo, facilitando a coleta coletiva.

Após todos estes impasses, ainda foi necessário um acordo da APAS com o PROCON (Programa de Proteção e Defesa do Consumidor) para a distribuição gratuita de duas sacolas por compra por um período de dois meses, para facilitar a adaptação do consumidor. A maior parte dos estabelecimentos está comercializando, as sacolas excedentes ao custo de $\mathrm{R} \$ 0,08$ a $\mathrm{R} \$ 0,10$ (aproximadamente $80 \%$ mais barato que em 2012). Isso garante o consumo consciente, pois o custo é relativamente baixo e fortalece a mensagem de separação do lixo. Tem-se, ainda, a opção de levar sacola própria aos estabelecimentos, evitando o consumo das sacolas bioplásticas e diminuindo a geração de resíduos.

Com esse estudo de caso podemos visualizar como o desenvolvimento sistemático e a padronização de uma solução especifica para a realidade local é importante para consolidar a lei, facilitando a adaptação dos consumidores e contribuindo para o consumo consciente.

\subsection{O design como ferramenta para o desenvolvimento de soluções}

Em bens de consumo, o design tem um importante papel, desempenhado por atribuições práticas e emocionais. Um exemplo, é o uso de sacolas com marcas renomadas, essas muitas vezes são reutilizadas para transportar produtos de marcas inferiores, estabelecendo uma relação prática de transporte e status. O mapeamento da cultura, dos contextos, das experiências pessoais e dos processos da vida dos indivíduos são campos de pesquisa para o design, que deve identificar as barreiras e, através da geração de alternativas, superá-las (VIANNA et al, 2012).

Além dos aspectos de preço, desempenho, legislação, cultura, aparência, os aspectos de sustentabilidade são fundamentais. A analise do ciclo de vida da sacola deve ser considerado desde o inicio do desenvolvimento, conforme explica Vezzoli \& Manzini (2008), porém, esse é um grande desafio para o designer sendo necessário levantar informações e entender cada variável de input (extração de substâncias do meio ambiente) e output (emissão de substâncias ao meio ambiente), como por exemplo impactos a camada de ozônio, emissões tóxicas, resíduos, entre outros efeitos. No entanto, o levantamento das informações sobre os impactos ambientais se 
mostra como um dos maiores desafios no desenvolvimento da analise do ciclo de vida conforme exposto por Manzini \& Vezzoli (2011).

Também o ecodesign deve ser considerado, avaliando como a configuração da nova embalagem poder reduzir os impactos ao meio ambiente. Para El-Haggar (2007) as sete regras de ouro (Regulamentação, Redução, Reuso, Reciclagem, Recuperar, Repensar e Renovar), devem ser seguidas como ferramentas básica para a poluição zero.

Verificamos assim a complexidade de um projeto para substituir uma simples sacola, exigindo uma ampla pesquisa, caso a caso para tomada de decisão assertiva. 0 que pode ser uma das explicações para a complexidade da mudança e a razão pela qual não foi efetivada em muitos municípios, embora a iniciativa governamental tenha sido tomada. Podemos compreender que as soluções mais simples demandam muito estudo e tempo.

\section{CONCLUSÃO}

O estudo das variáveis que envolvem as sacolas descartáveis produzidas com material derivado do petróleo evidenciou diversos pontos críticos motivando o seu banimento, como o seu consumo excessivo e tempo de degradação, por outro lado, as opções de sacola para sua substituição, disponíveis no mercado, não são tão ecológicas quanto deveriam, e tão pouco foram aceitas pelo consumidor na rotina de suas compras.

Por envolver questões culturais e sociais, esta não é uma mudança fácil, apontando para a necessidade de solução interdisciplinar, no qual o design deve ser utilizado como ferramenta para geração de ecobag que substitua de forma efetiva as sacolas descartáveis de petróleo.

$\mathrm{Na}$ definição do material a ser utilizado, deve-se considerar seu ciclo de vida, levando em conta a diferente realidade de cada município, e gerando solução especifica para cada região. Uma solução focada e aplicada juntamente com a lei mostra-se como uma solução viável, como exposto na cidade de São Paulo onde a resistência da população e de órgãos de defesa do consumidor foi vencida com o desenvolvimento de uma solução de sacola, planejada e padronizada. O design, nesse caso, teve o papel de complementar e regulamentar a Lei possibilitando sua aplicação, além de facilitar o entendimento das questões de uso e ambientais para os consumidores. Isso tende, em longo prazo, a contribuir para a mudança comportamental da população e consequentemente, para a mudança cultural de consumo e de descarte.

Por fim, devemos entender o design, como um articulador de soluções que visem, primeiramente, o bem estar social e ambiental, de forma a beneficiar outros setores, como o industrial e o comercial. Desta forma, entende-se que a aplicação do design em futuros desenvolvimentos de ecobag, devem ser estudadas nos seus mais variados aspectos, o que virá a proporcionar melhores condições de vida para as futuras gerações.

\section{REFERÊNCIAS}


AMLURB. Sacolas Bioplásticas e a Coleta Seletiva da cidade de São Paulo. São Paulo: Prefeitura de São Paulo, 2015. Disponível na internet por http em:

<http://www.prefeitura.sp.gov.br/cidade/secretarias/servicos/amlurb/noticias/?p=18 8477>. Acesso em 10 de abril de 2015.

APAS. Belo Horizonte completa um ano sem sacolas descartáveis. Belo Horizonte, 2012. Disponível na internet por http em:

$<$ http://www.portalapas.org.br/m5_imprime.asp?cod_noticia=11827\&cod_pagina=1 222>. Acesso em 08 de dezembro de 2014.

AQUINO, Yara. Especialista Defende que Peso Máximo de Mochilas Seja $10 \%$ do Peso Corporal. São Paulo: Agencia Brasil, 2014. Disponível na internet por http em: <http://memoria.ebc.com.br/agenciabrasil/noticia/2014-01-15/especialista-defendeque-peso-maximo-de-mochilas-seja-10-do-peso-corporal >. Acesso em 22 de março de 2015.

ASSOCIAÇÃO COMERCIAL SÃO PAULO. Dúvidas Frequentes Sobre a Lei 15.374/2011 “ Lei da Sacolinha". São Paulo: 2015. Disponível na internet por http em:

$<$ http://portal.acsp.com.br/assets/pdf/manuais-e-

cartilhas/Orienta\%C3\%A7\%C3\%B5es_Lei15374.pdf>. Acesso em 08 de abril de 2015.

BARBOSA, Vanessa de. Lugares no mundo que baniram ou taxaram o uso de sacola plástica. Brasil, 2012. Disponível na internet por http em:

<http://exame.abril.com.br/mundo/noticias/12-lugares-no-mundo-que-baniram-outaxaram-o-uso-de-sacola-plastica>. Acesso em 08 de dezembro de 2014.

BONATO, José. Cidades de SP obrigam supermercados a dar de novo sacolas plásticas. Ribeirão Preto: 2012. Disponível na internet por http em: <http://economia.uol.com.br/ultimas-noticias/redacao/2012/05/31/cidades-de-spobrigam-supermercados-a-dar-de-novo-sacolas-plasticas.jhtm >. Acesso em 05 de julho de 2015.

BONI, C. R.; SILVA, K.; SILVA, J. C. P. A 2014. (In)Definição do Design: Os Limites do Design e a Relação com a Arte e a Indústria. Anais do $11^{\circ}$ Congresso Brasileiro de Pesquisa e Desenvolvimento em Design. ISSN: 2318-6968. Disponível na internet por http em: <http://www.proceedings.blucher.com.br/article-list/11ped-233/list>. Acesso em 02 de dezembro de 2014.

BORGES, Marco André; MONTEIRO, Luís Carlos; LOBO, Alfredo Carlos Ophão.

Relatório sobre análise em sacolas plásticas de supermercado: Análise de produto. Brasil, 2011. Disponível na internet por http em:

<http://repositorios.inmetro.gov.br/handle/10926/1631>. Acesso em 15 de março de 2015.

COSTA, Daiane. Lei contra sacolas plásticas não pega no Rio. Rio de Janeiro: 2015. 
Disponível na internet por http em: <http://oglobo.globo.com/economia/defesa-doconsumidor/lei-contra-sacolas-plasticas-nao-pega-no-rio-15876913>. Acesso em 15 de abril de 2015.

EL-HAGGAR, Salah.Sustainable Industrial Design and Waste Management: Cradle-toCradle for Sustainable Development. London: Elsevier, 2007. Disponível na internet por http em:

<https://thecitywasteproject.files.wordpress.com/2013/03/sustainable_industrial_de sign_and-waste-management.pdf>. Acesso em 05 de julho de 2015.

ENVIRONMENT AGENCY.Lifecycle assessment of supermarket carrier bags available in 2006. Bristol, 2011. 120p. Disponível na internet por http em:

<https://www.gov.uk/government/uploads/system/uploads/attachment_data/file/29 1023/scho0711buan-e-e.pdf> Acesso em 11 de maio de 2015.

GREENPEACE. Lixo que Cruza Fronteiras. Brasil, 2010. Disponível na internet por http em: <http://www.greenpeace.org/brasil/pt/Noticias/Lixo-que-cruza-fronteiras/>. Acesso em 14 de abril de 2015.

MANZINI, Enzio;VEZZOLI, Carlo. O desenvolvimento de produtos sustentáveis: Os requisitos ambientais dos produtos industriais. Tradução de Astrid de Carvalho. 3 ed. São Paulo: Editora da Universidade de São Paulo, 2011.

MINISTÉRIO DO MEIO AMBIENTE.Saco é um saco. São Paulo: O tamanho do problema, 2009. Disponível na internet por http em:

<http://www.mma.gov.br/responsabilidade-socioambiental/producao-e-consumosustentavel/saco-e-um-saco/saiba-mais>. Acesso em 14 de abril de 2015.

PEREIRA, Daniel. Sacolas plásticas X meio ambiente. São Paulo: Ser Melhor, 2007.

Disponível na internet por http em:

$<$ http://www.sermelhor.com/artigo.php?artigo=56\&secao=ecologia>. Acesso em 21 de junho de 2015.

PRODANOV, Cleber Cristiano; FREITAS, Ernani Cesar. Metodologia do trabalho científico: métodos e técnicas da pesquisa e do trabalho acadêmico. Novo Hamburgo: Feevale, 2013. 2 ed. Disponível na internet por http em: <http://www.faatensino.com.br/wp-content/uploads/2014/11/2.1-E-bookMetodologia-do-Trabalho-Cientifico-2.pdf>. Acesso em 27 de julho de 2015.

REDIG,Joaquim. Não há cidadania sem informação, nem informação sem design. Revista Brasileira de Design da Informação: 2004. ISSN 1808-5377. Disponível na internet por http em:

<http://infodesign.emnuvens.com.br/public/journals/1/No.1Vol.12004/InfoDesign_v 1_n1_2004_04_Redig.pdf?download=1\&phpMyAdmin=H8DwcFLEmv4B1mx8YJNY1M FYs4e>. Acesso em 08 de dezembro de 2014.

SANTIAGO, Tatiana. Supermercados vão cobrar por sacolinhas a partir de domingo. 
São Paulo: 2015. Disponível na internet por http em: <http://g1.globo.com/saopaulo/noticia/2015/04/supermercados-vao-cobrar-por-sacolinhas-partir-dedomingo.html>. Acesso em 14 de abril de 2015.

SANTOS, A. S. F. et al. 2012. Sacolas plásticas: destinações sustentáveis e alternativas de substituição. Polímeros. v. 22, n. 3, p. 228-237.

SEVERINO, Antônio Joaquin. Metodologia do trabalho científico. São Paulo: Cortez, 2007.

THE CONSUMER GOODS FORUM. Global Protocol on Packaging Sustainability 2.0 Guidance.France, 2011. Disponível na internet por http em:

<http://www.theconsumergoodsforum.com/download-global-protocol-on-packagingsustainability-gpps>. Acesso em 08 de dezembro de 2014.

VEZZOLI, Carlo;MANZINI, Ezio. Design for Environmental Sustainability. Milan: Ed. Springer, 2008.

VIANNA, Maurício et al. DesignThinking: Inovação em Negócios. Rio de Janeiro; MJV Press, 2012. 